Archives of Agriculture and Environmental Science

\title{
A review on aflatoxins in stored grain food, their sources, mechanisms and possible health hazard
}

\author{
Anjan Chandra Sharma ${ }^{1}$, Ram Proshad ${ }^{2 *}$ (D), Tapos Kormoker ${ }^{3}$, Md. Saiful Islam ${ }^{2,4}$ and Krishno \\ Chandra $^{5}$ \\ ${ }^{1}$ Faculty of Agriculture, Patuakhali Science and Technology University, Dumki, Patuakhali-8602, BANGLADESH \\ ${ }^{2}$ Department of Soil Science, Patuakhali Science and Technology University, Dumki, Patuakhali-8602, BANGLADESH \\ ${ }^{3}$ Department of Emergency Management, Patuakhali Science and Technology University, Dumki, Patuakhali-8602, BANGLADESH \\ ${ }^{4}$ Laboratory of Plant Nutrition and Fertilizers, Graduate School of Agricultural and Life Sciences, The University of Tokyo, JAPAN \\ ${ }^{5}$ Department of Chemistry, Govt. Saadat College, Karatia, Tangail, BANGLADESH \\ *Corresponding author's E-mail: ramproshadpstu03470@gmail.com
}

\section{ARTICLE HISTORY}

Received: 10 October 2018

Revised received: 18 November 2018

Accepted: 22 November 2018

\section{ABSTRACT}

The aflatoxin producing fungi Aspergillus flavus, Aspergillus parasiticus, and Aspergillus nomius are highly hepatotoxic, carcinogenic and immunosuppressive which can spread quickly in environment and contaminate stored food. It can lead to serious threats to both human and animal health hazards by causing various diseases. Aflatoxin can breakdown DNA and causes genomic damage during cell division, leading to cancer even death where these breakdown products accumulate in the liver. The chemistry and biosynthesis process of the aflatoxin is discussed in present review study in a nutshell along with their occurrences and the health hazards to human. This review focuses on sources, production, biosynthesis, toxicology, detection, and control techniques of aflatoxins to assure food safety. Present review study is valuable as it provides knowledge on aflatoxins toxicity which helps in food security and safety as well as reduces human diseases in future.

(C)2018 Agriculture and Environmental Science Academy

\section{Keywords}

Aflatoxins

Aspergillus spp.

Cancer risk

Human health

Stored grain food Citation of this article: Sharma, A.C., Proshad, R., Kormoker, T., Islam, M.S. and Chandra, K. (2018). A review on aflatoxins in stored
grain food, their sources, mechanisms and possible health hazard. Archives of Agriculture and Environmental Science, 3(4): 416-423, https://dx.doi.org/10.26832/24566632.2018.0304015

\section{INTRODUCTION}

Aflatoxins are mostly toxic secondary fungal metabolites which are derived from some certain strains of fungi such as species of Aspergillus, specifically Aspergillus flavus, Aspergillus parasiticus (Figure 1) (Giray et al., 2007; Kumar et al., 2008) and that can quickly absorb by blood cells in human body if consume any aflatoxin contaminated food. Aflatoxins also known as potent and harmful groups of mycotoxins. Aflatoxin $B_{1}\left(A F B_{1}\right), A F B_{2}, A F G_{1}$ and $A F G_{2}$ are found mostly in nature and more than 20 types of aflatoxin identified (Figure 2) (Giray et al., 2007). The most important foods such as wheat, maize, rice, groundnuts, dried fruit, pearl millet, tree nuts (almonds, pecans, walnuts), black pepper, coriander, turmeric, zinger cocoa beans etc. are mostly contaminated by aflatoxins (Giray, et al., 2007; Bbosa, et al., 2013; Smith et al., 2015). Highly vulnerable crop in Bangladesh that contaminated by aflatoxins is maize (67\%), it was collected from farmers' stored grain in which average aflatoxin $B_{1}$ content found $33 \mathrm{microg} / \mathrm{kg}$ and maximum was found $245 \mathrm{microog} / \mathrm{kg}$ (Dawlatana, 2002). AFB 1 was identified in 58 organic spice and 32 organic herb samples, among organic spice samples and organic herbs sample, the maximum concentration of $A_{F B}$ was detected respectively in cinnamon sample $(53 \mu \mathrm{g} / \mathrm{kg})$ and rosehip sample $(52.5 \mu \mathrm{g} / \mathrm{kg}$ ) (Tosun and Arslan, 2013). These types of fungi are also commonly found in stored agricultural commodities such as corn, millet, sesame seeds, sorghum, sunflower seeds and different types of spice for keeping in improper storage (Figure 3). If this infected food (with aflatoxins containing fungi) is processed, then aflatoxins can enter the processed food and that are harmful for human health and also animals by affecting several problems. Children are frequently suffered by the exposure of aflatoxins, which results to stunted 
growth, delayed growth and development (Turner et al., 2007; Voth-Gaeddert et al., 2018), liver damage and finally liver cancer. Adults are capable to tolerate a higher level of aflatoxins exposure, but they should be conscious. The symptoms of severe aflatoxicosis include hemorrhagic necrosis of the liver, bile duct proliferation, edema, lethargy and death also observed (Williams et al., 2004; Kumar et al., 2008). It was firstly conscious in the Spring of 1960 by discovering the main cause of "turkey $X$ disease" in Great Britain, England (Wannop, 1961). A. flavus responsible for some common clinical syndromes such as granulomatous sinusitis, keratitis, cutaneous aspergillosis, wound infection, osteomyelitis following trauma and inoculation, it also acts as agent of otitis, keratitis, pulmonary and systemic infec-

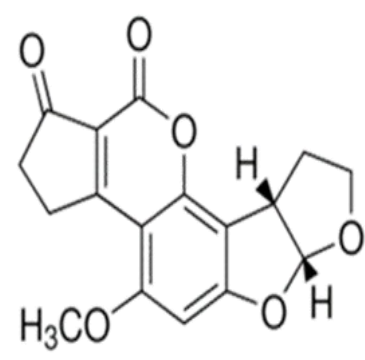

a

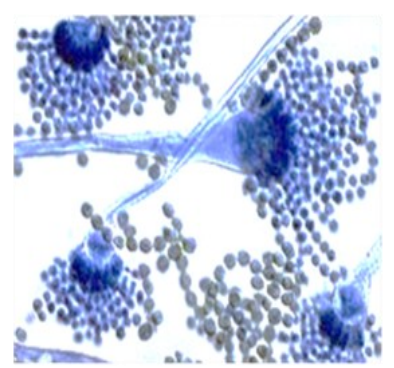

b
Figure 1. (a). Chemical formula of aflatoxin $B_{1}$ (b). Spores of $A$. flavus seen under microscope.

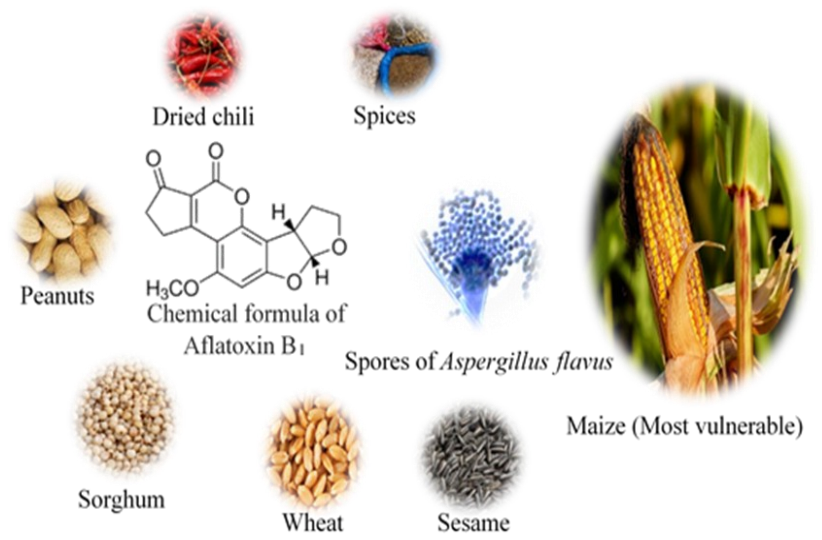

Figure 3. Crops that mostly contaminated by the species of Aspergillus. tions in immunocompromised patients (Hedayati et al., 2007). Aflatoxins contaminated food cannot be destroyed by normal process of cooking (Kumar et al., 2017). Enzymes of liver can breakdown aflatoxins and the breakdown products intercalate DNA and causes genomic damage during cell division that causes to cancer where these breakdown products accumulate in the liver to create liver cancer. It also estimated that due to harmful effect of aflatoxins, approximately $25 \%$ of agricultural products damaged worldwide (Yard, 2013). A research conducted by International Agency for Research on Cancer (IARC) in 1993 and informed that aflatoxins are class 1 toxic chemical compounds and responsible for causing human carcinogen, here given characteristics of aflatoxins in Table 1 (Kumar et al., 2008).

\section{Sources of aflatoxins producing fungi}

Aspergillus flavus, A. parasiticus, and A. nomius (Kurtzman et al., 1987) are the major source of different aflatoxin which are commonly grow in soil, particularly oil-rich seeds, grains living plants (Geiser et al., 2000) vegetation that decayed, crops residue such as hay, deterioration of microbiological activity and favorable environmental conditions more than $7 \%$ moisture and $20^{\circ} \mathrm{C}$ temperature. Many agricultural crops along with agricultural commodities are contaminate by these types of fungi during improper and delayed harvesting and post harvesting, storage and in processing. Corn and peanuts mostly contaminated by $A$. flavus and $A$. parasiticus respectively.
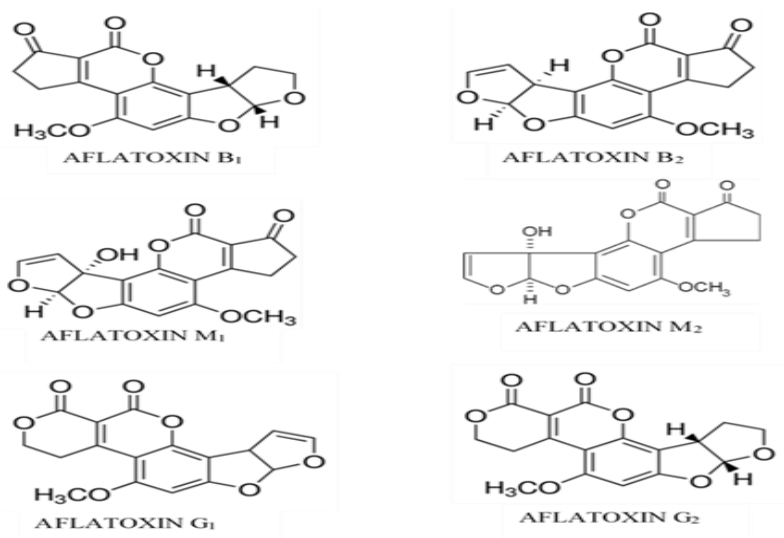

Figure 2. Several chemical structures of common aflatoxins found in stored grain foods.

Table 1. Characteristics of aflatoxins.

\begin{tabular}{ll}
\hline Effects & Characteristics of aflatoxins \\
\hline & Synergistic \\
Acute or chronic effects & Mutagenic \\
& Carcinogenic \\
& Cytotoxic \\
& Hepatotoxic \\
\cline { 2 - 2 } Effects of aflatoxins in molecular level & DNA mutations (Genetic disorder) \\
& Inhibit transcription and translation \\
& Proteins and nucleic acids cannot synthesize properly \\
& Genotoxic \\
& Inhibit normal process of Electron transport chain \\
\hline
\end{tabular}

Source: (Krishnamachari et al., 1975; Niranjan et al., 1982; Hsieh, 1987; Doi et al., 2002; Verma, 2004; Peterson et al., 2006; Hussain et al., 2007; Groopman et al., 2008; Wu et al., 2009) 
Favorable environment for growth of aflatoxins producing fungi and their expression

Optimum growth of Aspergillus parasiticus was analyzed at $35^{\circ} \mathrm{C}$ in the ranges $17-42^{\circ} \mathrm{C}$ temperature with varying combinations of 0.90-0.99 water activity $\left(a_{w}\right)$, that stimulate the regulatory genes' (aflR/aflS) expression levels and production of aflatoxin in A. flavus and A. parasiticus (Schmidt-Heydt et al., 2010). A. flavus can survive at temperature ranging from $12^{\circ} \mathrm{C}$ to $48^{\circ} \mathrm{C}$ (Hedayati et al., 2007). Water activity $\left(a_{w}\right)$ and optimum temperature have remarkable effect on species of Aspergillus and production of aflatoxins (Sanchis and Magan, 2004). The growth and production of $\mathrm{AFB}_{1}$ of $A$. flavus decreases under the temperature to $37^{\circ} \mathrm{C}$ during water stress. It was reported that growth of fungal biomass and $\mathrm{AFB}_{1}$ production was highest at $28^{\circ} \mathrm{C}$ temperature and 0.96 water activity, while no prominent fungal growth and $\mathrm{AFB}_{1}$ production detected at $20^{\circ} \mathrm{C}$ with the dried state condition at 0.90 and 0.93 water activity (Gallo et al., 2016; Kumar et al., 2017). Reverse transcriptase quantitative PCR also showed that in $28^{\circ} \mathrm{C}$ the two genes (aflR/aflS) were expressed highly and the greatest accumulation of fungal biomass appeared, while the lowest level of expression was detected at 20 and $37^{\circ} \mathrm{C}$, concluded that variation in temperature and in water activity $\left(\mathrm{a}_{\mathrm{w}}\right)$ plays very significant role in genes expression rate and production of aflatoxin (Gallo et al., 2016; Kumar et al., 2017).

Chemistry and biosynthesis of aflatoxins in human body by the species of Aspergillus

Different genes and enzymes that present in some species of aflatoxin producing fungi mainly in Aspergillus flavus also in Aspergillus parasiticus with factors affecting aflatoxin production have been reviewed (Yabe and Nakajima, 2004; Yu, 2012). About 30 aflatoxin pathway and 6 transcripts are identified through Aspergillus flavus EST and process about the Conversion of Acetate to Norsolorinic Acid (NOR) (Yu, 2012). A research conducted to investigate aflatoxin biosynthesis pathway by using cell-free enzyme systems prepared from Aspergillus parasiticus and elucidation about the novel metabolic grid that catalyzed by a new cytosol monooxygenase enzyme involved in aflatoxin biosynthesis (Yabe et al., 2003). A detailed study reviewed about biosynthesis and regulation of aflatoxins for reducing human exposure to aflatoxins as well as in how aflatoxin impacts human health (Roze et al., 2013).

\section{Molecular targets of aflatoxin in human body}

Normal function of gene expression and protein synthesis, normal metabolic activity inhibited by the effects of aflatoxin (Figure 4) (Kiessling, 1986). Mitochondrial respiration, cellular energy production, synthesis of macromolecule decreases by the effect of aflatoxins (Hsieh, 1987; Dhanasekaran et al., 2011). Somatic mutations progress by aflatoxins in the p53tumor suppressor gene (TP53) results to several genetic and epigenetic changes in the molecular pathogenesis of HCC (Hussain et al., 2007), p53 gene regulates the transcription of protective antioxidant genes and extensive DNA damage (Hussain et al.,

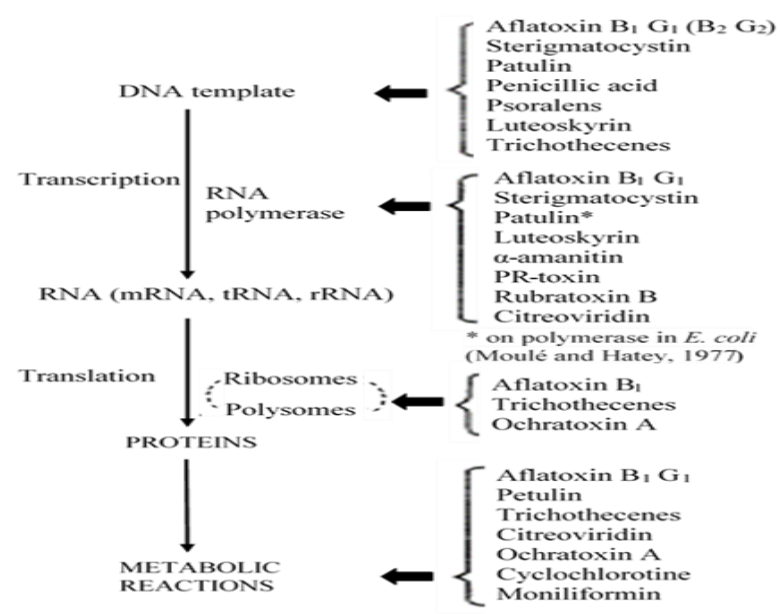

Figure 4. Mycotoxins affecting major sites in RNA and protein synthesis (adopted from Kiessling, 1986).

2007). Aflatoxins are inhibitors of nucleic acid synthesis because they have a high affinity for nucleic acids and polynucleotides that affect improper formation of organelles, DNA and other important metabolites (Dhanasekaran et al., 2011), so they cause several abnormalities in the structure and functioning of mitochondrial DNA and brain cells which are mainly due to adduct formation with DNA, RNA and protein, results to hepatotoxic, hepatocarcinogenic and mutagenic effects (Verma, 2004). Aflatoxin $B_{1}$ is capable of weak binding with singlestranded DNA but purine bases and amino group play a vital role in the binding of all the aflatoxin to DNA (Clifford and Rees, 1967). Interaction of aflatoxin $B_{1}$ with DNA investigated in more detail by the difference spectra of aflatoxin, mixed with various nucleosides and the results indicate that for the binding of aflatoxin to DNA the purine ring is important and the presence of an amino group on the ring also aids in the interaction (Clifford and Rees, 1967).

Metabolism and mechanisms of aflatoxin $\mathrm{B}_{1}$ in liver

Different types of enzymes remain in human liver and intestine, these microsomal enzymes induce to metabolize aftatoxin $B_{1}$ into other different metabolites through hydroxylation, hydration, demethylation and epoxidation (Figure 5), such as CYP450 enzymes can bioactivate $\mathrm{AFB}_{1}$ to an electrophilic, highly reactive and unstable metabolite that can react with cellular molecules such as DNA (causing genotoxicity), proteins (causing cytotoxicity in the cell of Hepa-1) and also produce Aflatoxicol if cytoplasmic reductase enzyme acts on aflatoxin $B_{1}$ (Doi et al., 2002; Dohnal et al., 2014). CYP1A2 and CYP3A4 enzymes also catalyzes biotransforming of $A F B_{1}$ to the toxic product $A F B_{1}-8,9$-epoxide ( $A F B O$ ) that is hepatocellular cancerogenic in nature and this process occurs through epoxidation and hydration of aflatoxin $\mathrm{B}_{1}$, which binds to DNA and alters gene expression they also cause lipids accumulation in the liver that results to liver very fatty (Dhanasekaran et al., 2011; Dohnal et al., 2014). Almost four metabolic pathways involve in toxic effect of $\mathrm{AFB}_{1}$, that are O-dealkylation to $\mathrm{AFP}_{1}$, ketoreduction to Aflatoxicol (AFL), epoxidation to $\mathrm{AFB}_{1}$-8,9-epoxide (highly toxic, mutagenic, and carcinogenic), and hydroxylation to AFM (highly toxic), $\mathrm{AFP}_{1}$, $\mathrm{AFQ}_{1}$ and $\mathrm{AFB}_{2 \mathrm{a}}$ (all relatively nontoxic) (Wu et al., 2009). 
Effects of aflatoxins on carbohydrate and lipid metabolism Aflatoxins (Aflatoxin $\mathrm{B}_{1}$ ) are harmful on oxidative phosphorylation of carbohydrate metabolism that reduced hepatic/liver glycogen and raise blood glucose levels by accelerating oxidation of glucose 6-phosphate, also involve in decreasing activities of glycogen phosphorylase, phosphoglucomutase which reversibly converts glucose 6-phosphate into glucose 1-phosphate (Figure 6) (Shankaran et al., 1970; Kiessling, 1986). Lipid metabolism cannot complete properly due to presence of aflatoxins that inhibits glycogen synthesis by decreasing enzymatic activities of glycogen synthetase and transglycosylase, these enzymes helps to catalyze elongation and rearrangement of the glycogen molecules and the experiment was checked in chickens (Shankaran et al., 1970; Tung et al., 1983). Additionally, hepatic glycogen reduces by accelerating glucose 6-phosphate oxidation (Kiessling, 1986).

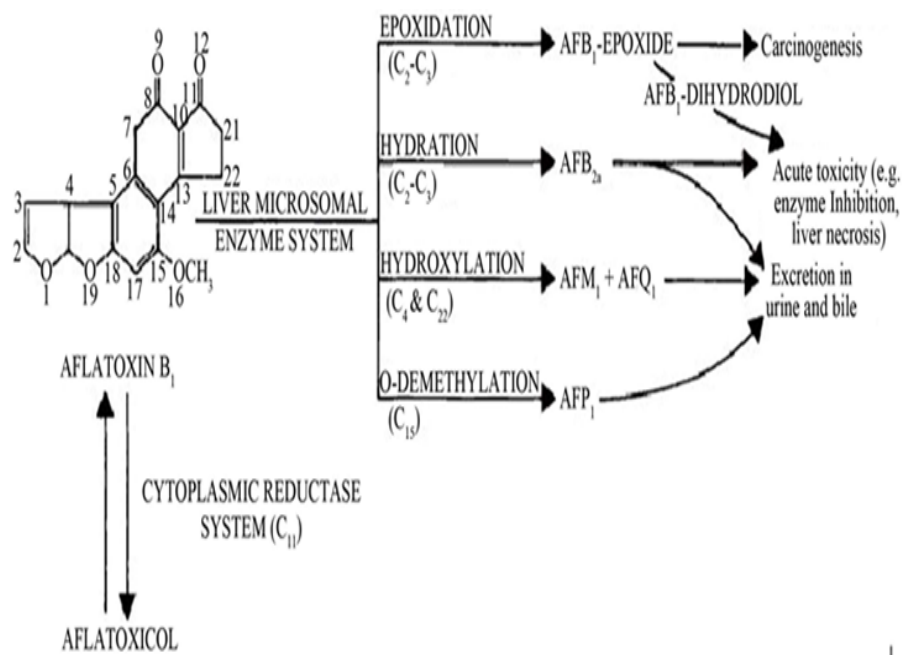

Figure 5. Metabolism of aflatoxins in liver (adopted from Dhanasekaran et al., 2011).

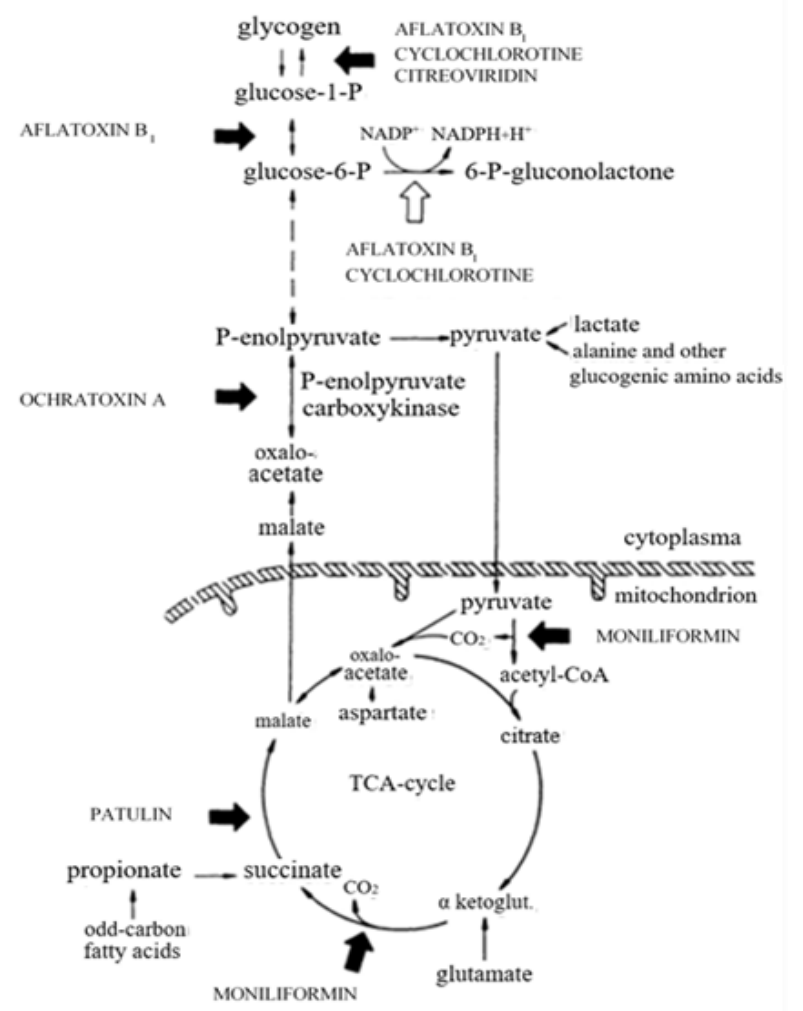

Figure 6. Sites where mycotoxins interfere with carbohydrate metabolism (adopted from Kiessling, 1986).
Effects of aflatoxins on electron transport chain (ETS) in mitochondria

Aflatoxin B1 inhibits the vital function of electron transport system in mitochondria at site II in cytochrome oxidase level, whereas the inhibition occurs between cytochrome b1 (cyt-b1) and c (Figure 7) (Kiessling, 1986). It was reported that $A F B_{1}$ are capable of covalently binding to mitochondrial DNA with a 3 to 4 times higher affinity than nuclear DNA, and the chemical modification or concentration of carcinogen adducts in mitochondrial DNA persists even after 24 hours, possibly because of lack of excision repair mechanisms (Niranjan et al., 1982). This effect results to mitochondrial transcription and translation that remain inhibited up to same time and suggested that it may happen for long-term effects of aflatoxin $B_{1}$ on the genetic system of mitochondria (the power house of cell) (Niranjan et al., 1982). Another research also reported that lesions (a region in an organ or tissue which has suffered damage) in mitochondrial DNA are persistent, possibly lack of same mechanisms in the organelle, results to inhibition of mitochondrial transcription and translation (Hsieh, 1987).

Effect of aflatoxin on Hepatitis B Virus (HBV) and Hepatitis C Virus (HCV) that induced to liver failure

If individuals affect by both interaction of aflatoxin $B_{1}$ and hepatitis $B$ virus (HBV) in same time leads to enhance the development of hepatocelllular carcinoma (HCC) (Figure 8) (Groopman et al., 2005; Hussain et al., 2007). It happens about 30 times greater than the risk in individuals exposed to only aflatoxin (Groopman et al., 2008; Liu and Wu, 2010). Synergistic effect of aflatoxins appeared on hepatitis $C$ virus that induced liver cancer (Kirk et al., 2006; Wild and Montesano, 2009; Liu and $\mathrm{Wu}, 2010)$. A research analyzed that there is a correlation with the presence of aflatoxins and increased liver cancer in individuals who are carrier of hepatitis B (Dhanasekaran et al., 2011). These viruses (HBV and HCV) induce liver injury, hepatocyte death and promote hepatocarcinogenesis (Hussain et al., 2007). A review explored about the independent and combined effects of hepatitis $B$ virus (HBV), hepatitis $C$ virus (HCV) and aflatoxin exposure responsible in the causes of HCC (Kirk et al., 2006).

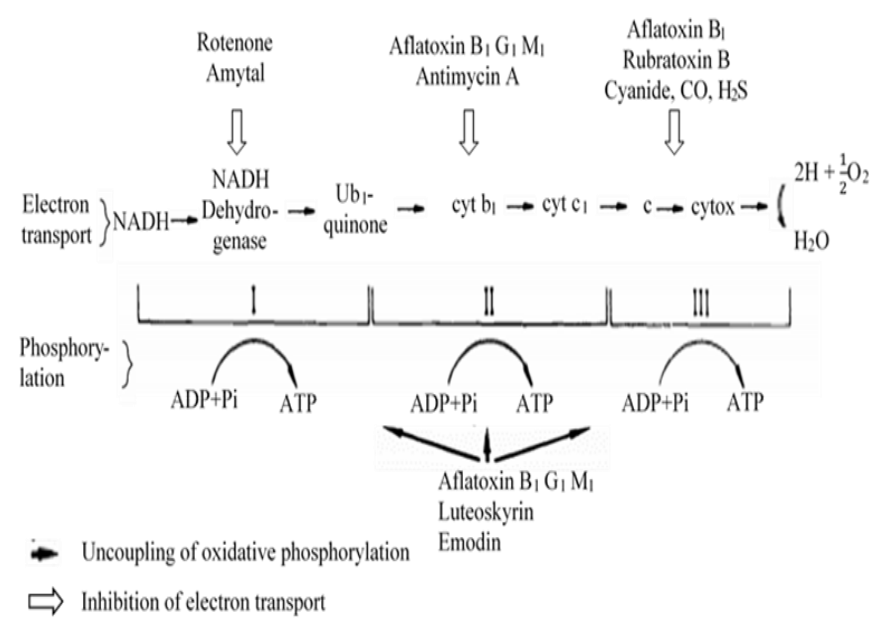

Figure 7. Aflatoxin inhibition of electron transport chain in oxidative phosphorylation (adopted from Kiessling, 1986). 


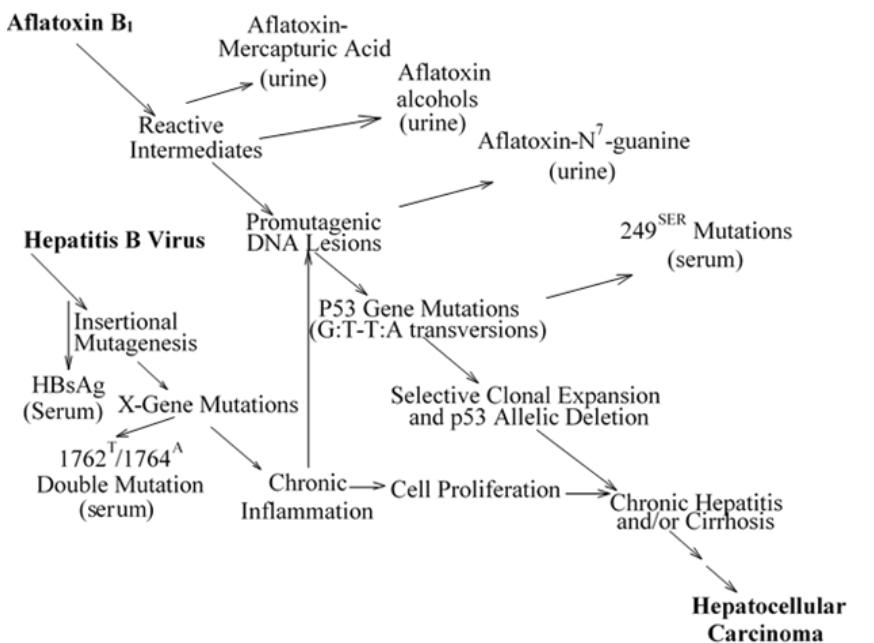

Figure 8. Potential molecular mechanisms of interaction between HBV and aflatoxin in the development of hepatocellular carcinoma, as elucidated by several biomarkers. HBsAg, hepatitis B surface antigen (adopted from Groopman et al., 2005).

Toxicity and toxic effect of aflatoxins in human health The severe or acute lethal dose of aflatoxins for adults is 10 to $20 \mathrm{mg}$ and the median lethal dose is $0.36 \mathrm{mg} / \mathrm{kg}$ in total body weight (Etzel, 2002; Dhanasekaran et al., 2011). The clinical manifestations of aflatoxicosis or disease symptoms are fever, malaise and anorexia followed with abdominal pain, high colored urine, vomiting, and edema of feet, Jaundice, rapidly developing Ascitis, pulmonary edema, portal hypertension, high mortality with sudden death, childhood cirrhosis, increases risk with a synergistic effect, swollen of gall bladder, decrease in Vitamin K activities (Krishnamachari et al., 1975; Groopman et al., 2008). Most people are at risk of chronic exposure around the world (Figure 9) (Dhanasekaran et al., 2011). Major histopathological diagnosis reported gastrointestinal bleeding, fatty infiltration, hepatic lesions, even hepatomas bile duct proliferation with periductal fibrosis and centrilobular necrosis (Krishnamachari et al., 975; Ngindu, et al., 1982; Groopman et al., 2008; Yu, 2012).

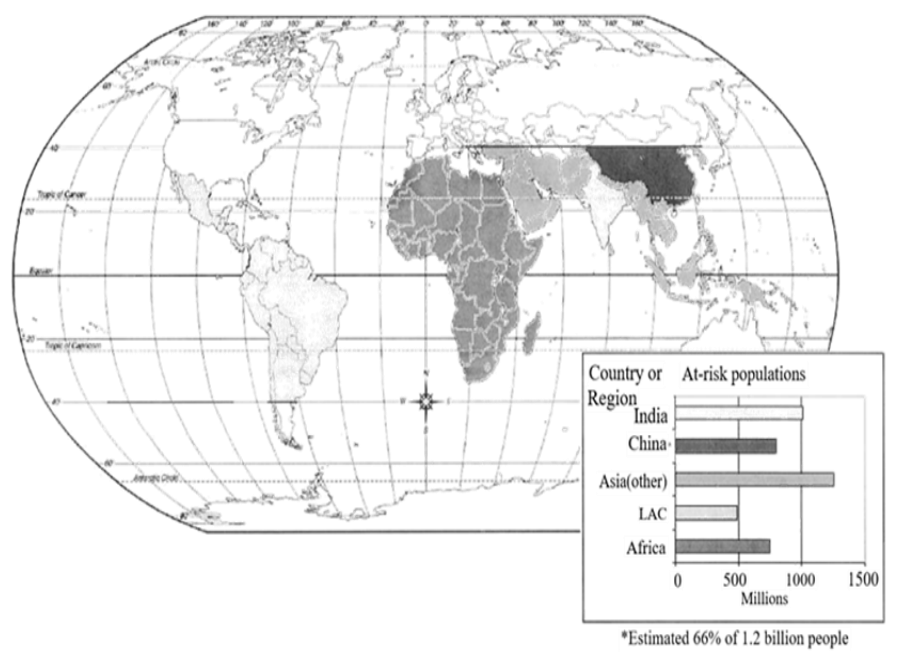

Figure 9. Areas and populations at risk of chronic exposure to uncontrolled aflatoxin. LAC, Latin America and the Caribbean (adopted from Williams et al., 2004).

Outbreaks due to effect of aflatoxins

At first, aflatoxins were isolated from turkeys and recognized as the harmful toxins of turkey " $X$ " disease in England and the affected birds died quickly (Wannop, 1961). In 1974, a major outbreak of hepatitis due to aflatoxin was reported in the states of Gujarat and Rajasthan in Western India, resulting in an estimated about 397 affected and 106 deaths for consuming of maize that was heavily contaminated by aflatoxin (Krishnamachari et al., 1975). Aflatoxin $B_{1}$ was detected in high concentration in the livers of those affected individuals who died and the outbreaks lasted for two months (Krishnamachari et al., 1975). Some Kenyan people also suffered in 1981 due to toxic effect of aflatoxin and number of affected and dead was 20 and 12 respectively (Ngindu et al., 1982). It was estimated that annually about 250,000 deaths occur in certain parts of China and sub-Saharan Africa due to hepatocellular carcinoma where high presence of aflatoxin in food (Yabe and Nakajima, 2004). The toxicity, toxic effect and outbreaks due to harmful impact of aflatoxins given at a glance in Table 2.

Table 2. Toxicity, toxic effect and outbreaks due to harmful impact of aflatoxins.

Toxicity, toxic effect and outbreaks due to harmful impact of aflatoxins

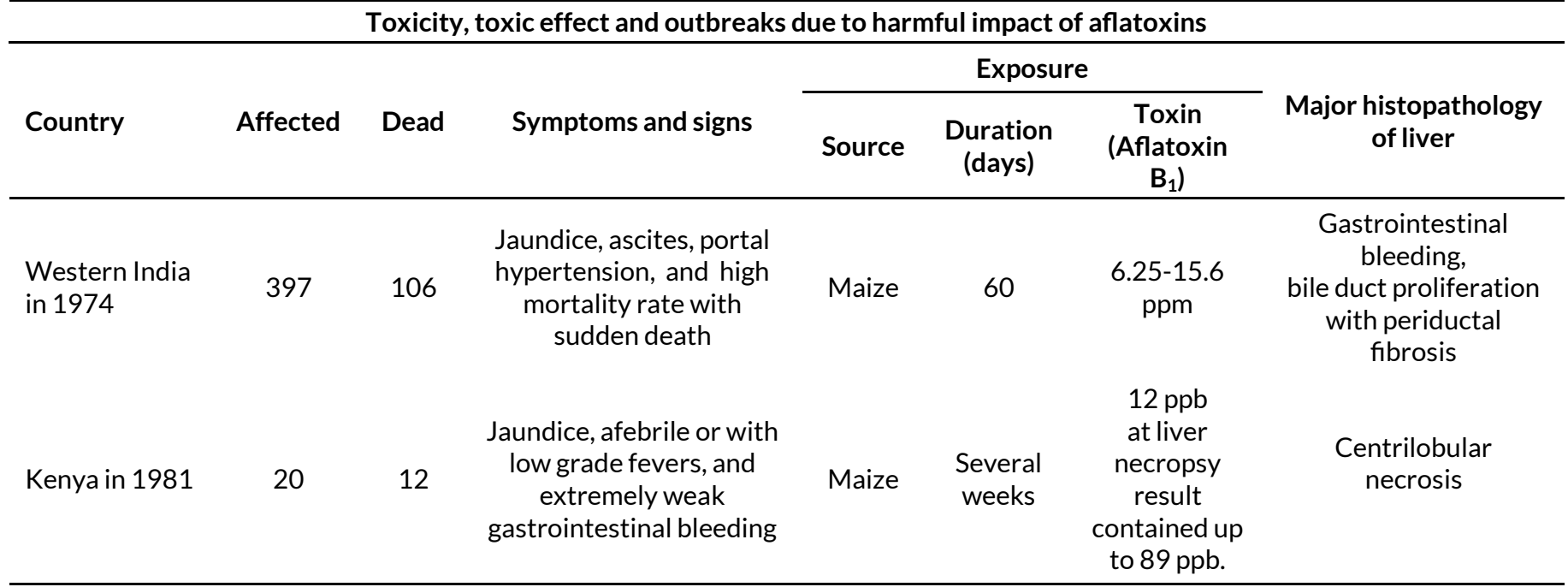


Detection techniques of aflatoxins

Presence of aflatoxins can be detected and identified according to their absorption and emission spectra, with peak absorbance occurring at $360 \mathrm{~nm}$ wave length. AFB toxins exhibit blue fluorescence at $425 \mathrm{~nm}$ wave length, while AFG toxins show green fluorescence at $540 \mathrm{~nm}$ wave length under UV radiation. This florescence phenomenon is widely accepted for aflatoxins detection while high performance liquid chromatography (HPLC), Liquid chromatography mass spectroscopy (LCMS), and enzyme linked immune-sorbent assay (ELISA) are the methods mostly used for its detection (Andrade et al., 2013; Sulyok et al., 2015; Kumar et al., 2017). Enzyme-linked Immunosorbent Assay (ELISA) used to identify aflatoxins based on estimation of $A_{f} B_{1}$ lysine (metabolite of $A F B_{1}$ toxin) concentration in the blood and the test can mainly detect the levels of $A F B_{1}$ in blood and can be used in detection of hepatitis B virus (Kumar et al., 2017).

\section{Management and control approaches}

Bacillus subtilis, Lactobacillus spp., Pseudomonas spp., Ralstonia spp. and Burkholderia spp. are effective as bio control agents to control aflatoxin producing Aspergillus flavus (Palumbo et al., 2006). A research was conducted to examine antagonistic activity against Aspergillus section Flavi strains by selecting bacterial isolates from the non-rhizophere of maize soil have been reported that strains of Bacillus subtilis and Pseudomonas solanacearum eliminated aflatoxin accumulation (Nesci et al., 2005). Several researches conducted about commodity-wise aetiology and contamination process about some crops such as groundnut, rice, maize, sorghum, spices and chilli (Kumar et al., 2008). Good agricultural practices and postharvest methods such as timely planting, providing adequate plant nutrition, controlling weeds, crop rotation, lowering moisture content during storage $(\leq 8 \%$ moisture level), adding preservatives to prevent insect infestation and fungal contamination during storage, sorting of contaminated pods and kernels, re-drying of groundnut pods and kernels, appropriate storage conditions to avoid favorable conditions for mold growth, avoidance of re-humidification of pods, detoxification of contaminated products, enhancing awareness of smallholders which effectively control A. flavus infection in the field and agricultural commodities, the study was conducted in groundnut (Waliyar et al., 2013). Some resistance-associated proteins of maize kernel endosperm that regulated by specific gene were identified by peptide sequencing and among them a stress-related peroxiredoxin antioxidant (PER1) was significantly induced upon A. flavus infection. Biotechnological approaches of genetic control and factors associated that affect biosynthesis of aflatoxin have been reviewed for aflatoxin management strategies (Yu, 2012). Genomic technology-based research developed for identification of the genes responsible for production and modification of the aflatoxin biosynthesis process (Cleveland et al., 2006; Holbrook et al., 2009). If a regular diet including apiaceous vegetables, such as carrots, parsnips, celery, parsley etc. can be maintained that are chemo-preventive and may reduce the carcinogenic effects of aflatoxin in humans (Peterson et al., 2006).
Conclusion

Aflatoxins (mainly aflatoxin $B_{1}$ ) are responsible for liver cancer that spread by contamination of Aspergillus spp. that mostly occurs by Aspergillus flavus. Outbreaks occur due to improper storage of agricultural commodities, lack of knowledge about the management of agricultural commodities and when we consume that contaminated food. In developing countries excessive levels of aflatoxins contamination in food requires major concern. Though, several techniques developed (physical, chemical, biological, and genetic engineering) that have been employed for the mitigation of aflatoxin, effective control and management need to be done for food safety worldwide.

Open Access: This is an open access article distributed under the terms of the Creative Commons Attribution 4.0 License, which permits unrestricted use, distribution, and reproduction in any medium, provided the original author(s) if the sources are credited.

\section{REFERENCES}

Andrade, P.D., da Silva, J.L.G. and Caldas, E.D. (2013). Simultaneous analysis of aflatoxins B1, B2, G1, G2, M1 and ochratoxin $A$ in breast milk by high performance liquid chromatography/fluorescence after liquid-liquid extraction with low temperature purification (LLE-LTP). Journal of Chromatography $A, \quad 1304:$ 61-68, https://doi.org/10.1016/ j.chroma.2013.06.049

Bbosa, G.S., Kitya, D., Lubega, A., Ogwal-Okeng, J., Anokbonggo, W.W. and Kyegombe, D.B. (2013). Review of the biological and health effects of aflatoxins on body organs and body systems, in: Razzaghi-Abyaneh, M. (Ed.), Aflatoxins - Recent Advances and Future Prospects, IntechOpen Access Publisher, United Kingdom, pp. 239-265, https:// doi.org/10.5772/51201

Cleveland, T.E., Yu, J., Chen, Z.Y., Brown, R.L., Cary, J.W., Rajasekaran, K., Bhatnagar, D., Campbell, B.C., Nierman, W.C. and Payne, G.A. (2006). The use of crop proteomics and fungal genomics in elucidating fungus-crop interactions. In Proceedings of the Myco-Globe Conference. pp, 32. Retrieved September 26-30, 2006, Bari, Italy from https:// www.ars.usda.gov/research/publications/publication? seqNo115=204057

Clifford, J.I. and Rees, K.R. (1967). The interaction of aflatoxins with purines and purine nucleosides. Biochemical Journal, 103(2): 467-471, https://doi.org/10.1042/bj1030467

Dawlatana, M., Coker, R.D., Nagler, M.J., Wild, C.P., Hassan, M.S. and Blunden, G. (2002). The occurrence of mycotoxins in key commodities in Bangladesh: surveillance results from 1993 to 1995. Journal of Natural Toxins, 11(4): 379-386.

Dhanasekaran, D., Shanmugapriya, S., Thajuddin, N. and Panneerselvam, A. (2011). Aflatoxins and aflatoxicosis in human and animals, in: Guevara-Gonzalez, R.G. (Ed.), Aflatoxins-Biochemistry and Molecular Biology, 
IntechOpen Access Publisher, United Kingdom, pp. 221256, https://doi.org/10.5772/22717

Dohnal, V., Wu, Q. and Kuča , K. (2014). Metabolism of aflatoxins: key enzymes and interindividual as well as interspecies differences. Archives of Toxicology, 88(9): 1635-1644, https://doi.org/10.1007/s00204-014-1312-9

Doi, A.M., Patterson, P.E. and Gallagher, E.P. (2002). Variability in aflatoxin $\mathrm{B}_{1}$-macromolecular binding and relationship to biotransformation enzyme expression in human prenatal and adult liver. Toxicology and Applied Pharmacology, 181: 48 -59, https://doi.org/10.1006/taap.2002.9399

Etzel, R.A. (2002). Mycotoxins. The Journal of the American Medical Association, 287(4): 425-427, https://doi.org/10.1001/jama.287.4.425

Gallo, A., Solfrizzo, M., Epifani, F., Panzarini, G. and Perrone, G. (2016). Effect of temperature and water activity on gene expression and aflatoxin biosynthesis in Aspergillus flavus on almond medium. International Journal of Food Microbiology, 217: 162-169, https://doi.org/10.1016/ j.ijfoodmicro.2015.10.026

Geiser, D.M., Dorner, J.W., Horn, B.W., and Taylor, J.W. (2000). The phylogenetics of mycotoxin and sclerotium production in Aspergillus flavus and Aspergillus oryzae. Fungal Genetics and Biology, 31(3): 169-179, https://doi.org/10.1006/ fgbi.2000.1215

Giray, B., Girgin, G., Engin, A.B., Aydın, S. and Sahin, G. (2007). Aflatoxin levels in wheat samples consumed in some regions of Turkey. Food Control, 18(1): 23-29, https:// doi.org/10.1016/j.foodcont.2005.08.002

Groopman, J.D., Johnson, D. and Kensler, T.W. (2005) Aflatoxin and hepatitis $B$ virus biomarkers: A paradigm for complex environmental exposures and cancer risk. Cancer Biomarkers, 1(1): 5-14, https://doi.org/10.3233/cbm-20051103

Groopman, J.D., Kensler, T.W. and Wild, C.P. (2008) Protective interventions to prevent aflatoxin-induced carcinogenesis in developing countries. Annual Review of Public Health, 29 (1): 187-203, https://doi.org/10.1146/ annurev.publhealth.29.020907.090859

Hedayati, M.T., Pasqualotto, A.C., Warn, P.A., Bowyer, P. and Denning, D.W. (2007). Aspergillus flavus: human pathogen, allergen and mycotoxin producer. Microbiology, 153(6): 16771692, https://doi.org/10.1099/mic.0.2007/007641-0

Holbrook, C.C., Guo, B., Wilson, D.M. and Timper, P. (2009). The U.S. breeding program to develop peanut with drought tolerance and reduced aflatoxin contamination. Peanut Science, 36(1): 50-53, https://doi.org/10.3146/at07-009.1

Hsieh, D.P.H. (1987). Mode of action of mycotoxins, in: Krogh, P. (Ed.), Mycotoxins in Food, Cambridge Academic Press, pp. 149-176.

Hussain, S.P., Schwank, J., Staib, F., Wang, X.W. and Harris, C.C. (2007). TP53 mutations and hepatocellular carcinoma: insights into the etiology and pathogenesis of liver cancer. Oncogene, 26 (15): 2166-2176, https://doi.org/10.1038/ sj.onc.1210279
Kiessling, K.H. (1986). Biochemical mechanism of action of mycotoxins. Pure and Applied Chemistry, 58(2): 327-338, https://doi.org/10.1351/pac198658020327

Kirk, G.D., Bah, E. and Montesano, R. (2006). Molecular epidemiology of human liver cancer: insights into etiology, pathogenesis and prevention from The Gambia, West Africa. Carcinogenesis, 27(10): 2070-2082, https://doi.org/10.1093/carcin/bgl060

Krishnamachari, K.A.V.R., Nagarajan, V., Bhat, R. and Tilal, T.B.G. (1975). Hepatitis due to aflatoxicosis: an outbraek in western India. The Lancet, 305(7915): 1061-1063, https://doi.org/10.1016/S0140-6736 (75)91829-2

Kumar, P., Mahato, D.K., Kamle, M., Mohanta, T.K. and Kang, S.G. (2017). Aflatoxins: a global concern for food safety, human health and their management. Frontiers in Microbiology, 7: 2170, https://doi.org/10.3389/fmicb.2016.02170

Kumar, V., Basu, M.S. and Rajendran, T.P. (2008). Mycotoxin research and mycoflora in some commercially important agricultural commodities. Crop Protection, 27(6): 891-905, https://doi.org/10.1016/j.cropro.2007.12.011

Kurtzman, C.P., Horn, B.W. and Hesseltine, C.W. (1987). Aspergillus nomius, a new aflatoxin-producing species related to Aspergillus flavus and Aspergillus parasiticus. Antonie Van Leeuwenhoek, 53(3): 147-158, https:// doi.org/10.1007/bf00393843

Liu, Y. and Wu, F. (2010). Global burden of aflatoxin-induced hepatocellular carcinoma: a risk assessment. Environmental Health Perspectives, 118(6): 818-824, https:// doi.org/10.1289/ehp.0901388

Moulé, Y. and Hatey, F. (1977). Mechanism of the in vitro inhibition of transcription by patulin, a mycotoxin from Byssochlamys nivea. FEBS letters, 74(1): 121-125, https:// doi.org/10.1016/0014-5793(77)80767-9

Nesci, A.V., Bluma, R.V. and Etcheverry, M.G. (2005). In vitro selection of maize rhizobacteria to study potential biological control of Aspergillus section Flavi and aflatoxin production. European Journal of Plant Pathology, 113(2): 159-171, https://doi.org/10.1007/s10658-005-5548-3

Ngindu, A., Kenya, P., Ocheng, D., Omondi, T., Ngare, W., Gatei, D., Johnson, B., Ngira, J., Nandwa, H., Jansen, A., Kaviti, J. and Siongok, T.A. (1982). Outbreak of acute hepatitis caused by aflatoxin poisoning in Kenya. The Lancet, 319 (8285): 1346-1348, https://doi.org/10.1016/s0140-6736 (82) $92411-4$

Niranjan, B.G., Bhat, N.K. and Avadhani, N.G. (1982) Preferential attack of mitochondrial DNA by aflatoxin $B_{1}$, during hepatocarcinogenesis. Science, 215(4528): 73-75, https:// doi.org/10.1126/science.6797067

Palumbo, J.D., Baker, J.L. and Mahoney, N.E. (2006). Isolation of bacterial antagonists of Aspergillus flavus from almonds. Microbial Ecology, 52(1): 45-52, https://doi.org/10.1007/ s00248-006-9096-y

Peterson, S., Lampe, J.W., Bammler, T.K., Gross-Steinmeyer, K. and Eaton, D.L. (2006). Apiaceous vegetable constituents inhibit human cytochrome P-450 1A2 (hCYP1A2) activity 
and hCYP1A2-mediated mutagenicity of aflatoxin $\mathrm{B}_{1}$. Food and Chemical Toxicology, 44(9): 1474-84, https://doi.org/10.1016/j.fct.2006.04.010

Roze, L.V., Hong, S-Y., and Linz, J.E. (2013). Aflatoxin biosynthesis: current frontiers. Annual Review of Food Science and Technology, 4: 293-311, https://doi.org/10.1146/annurevfood-083012-123702

Sanchis, V. and Magan, N. (2004). Environmental conditions affecting mycotoxins, in: N. Magan, N. and Olsen, M. (Eds.), Mycotoxins in food: Detection and control, Woodhead Publishing Ltd., Cambridge, England, pp. 174-189.

Schmidt-Heydt, M., Rufer, C.E., Abdel-Hadi, A., Magan, N. and Geisen, R. (2010). The production of aflatoxin $B_{1}$ or $G_{1}$ by Aspergillus parasiticus at various combinations of temperature and water activity is related to the ratio of aflS to aflR expression. Mycotoxin Research, 26(4): 241-246, https://doi.org/10.1007/s12550-010-0062-7

Shankaran, R., Raj, H.G. and Venkitasubramanian, T.A. (1970). Effect of aflatoxin on carbohydrate metabolism in chick liver. Enzymologia, 39(6): 371-378.

Smith, L.E., Prendergast, A.J., Turner, P.C., Mbuya, M.N.N., Mutasa, K., Kembo, G., and Stoltzfus, R.J. (2015). The potential role of mycotoxins as a contributor to stunting in the SHINE trial. Clinical Infectious Diseases, 61(Suppl 7), S733-S737, https://doi.org/10.1093/cid/civ849

Sulyok, M., Beed, F., Boni, S., Abass, A., Mukunzi, A. and Krska, R. (2015). Quantitation of multiple mycotoxins and cyanogenic glucosides in cassava samples from Tanzania and Rwanda by an LC-MS/MS-based multi-toxin method. Food Additives and Contaminants: Part A, 32(4): 488-502, https://doi.org/10.1080/19440049.2014.975752

Tosun, H. and Arslan, R. (2013). Determination of aflatoxin B1 levels in organic spices and herbs. The Scientific World Journal, 2013: 1-4, https://doi.org/10.1155/2013/874093

Tung, H.T., Donaldson, W.E., and Hamilton, P.B. (1983). Altered lipid transport during aflatoxicosis. Toxicology and Applied Pharmacology, 22(1): 97-104, https://doi.org/10.1016/0041-008x(72)90229-3

Turner, P.C., Collinson, A.C., Cheung, Y.B., Gong, Y., Hall, A.J., Prentice, A.M. and Wild, C.P. (2007). Aflatoxin exposure in utero causes growth faltering in Gambian infants. International Journal of Epidemiology, 36(5): 1119-1125, https://doi.org/10.1093/ije/dym122

Verma, R.J. (2004). Aflatoxin cause DNA damage. International Journal of Human Genetics, 4(4): 231-236, https:// doi.org/10.1080/09723757.2004.11885899
Voth-Gaeddert, L.E., Stoker, M., Torres, O. and Oerther, D.B. (2018). Association of aflatoxin exposure and heightfor-age among young children in Guatemala. International Journal of Environmental Health Research, 28(3): 1-13, https://doi.org/10.1080/09603123.2018.1468424

Waliyar, F., Osiru, M., Ntare, B.R., Kumar, K.V.K., Sudini, H., Traore, A. and Diarra, B. (2014). Post-harvest management of aflatoxin contamination in groundnut. World Mycotoxin Journal, 8(2): 245-252, https://doi.org/10.3920/ wmj2014.1766

Wannop, C.C. (1961). The histopathology of turkey "X" disease in Great Britain. Avian Diseases, 5(4): 371-381, https://doi.org/10.2307/1587768

Wild, C.P. and Montesano, R. (2009). A model of interaction: aflatoxins and hepatitis viruses in liver cancer aetiology and prevention. Cancer Letters, 286(1): 22-28, https:// doi.org/10.1016/j.canlet.2009.02.053

Williams, J.H., Phillips, T.D., Jolly, P.E., Stiles, J.K., Jolly, C.M. and Aggarwal, D. (2004). Human aflatoxicosis in developing countries: a review of toxicology, exposure, potential health consequences, and interventions. The American Journal of Clinical Nutrition, 80(5): 1106-1122, https://doi.org/10.1093/ajcn/80.5.1106

Wu, Q., Jezkova, A., Yuan, Z., Pavlikova, L., Dohnal, V. and Kuca, K. (2009). Biological degradation of aflatoxins. Drug Metabolism Reviews, 41(1): 1-7, https://doi.org/10.1080/03602530802563850

Yabe, K. and Nakajima, H. (2004). Enzyme reactions and genes in aflatoxin biosynthesis. Applied Microbiology Biotechnology, 64 (6): 745-755, https://doi.org/10.1007/s00253-004-1566-x

Yabe, K., Chihaya, N., Hamamatsu, S., Sakuno, E., Hamasaki, T., Nakajima, H. and Bennett, J.W. (2003). Enzymatic conversion of averufin to hydroxyversicolorone and elucidation of a novel metabolic grid involved in aflatoxin biosynthesis. Applied and Environmental Microbiology, 69(1): 66-73, https://doi.org/10.1128/aem.69.1.66-73.2003

Yard, E.E., Daniel, J.H., Lewis, L.S., Rybak, M.E., Paliakov, E.M., Kim, A.A., Montgomery, J. M., Bunnell, R., Abud, M.U., Akhwale, W., Breiman, R.F. and Sharif, S.K. (2013). Human aflatoxin exposure in Kenya, 2007: a cross-sectional study. Food Additives Contaminants: Part A, 30(7): 1322-31, https://doi.org/10.1080/19440049.2013.789558

$\mathrm{Yu}$, J. (2012). Current understanding on aflatoxin biosynthesis and future perspective in reducing aflatoxin contamination. Toxins, 4(11): 1024-1057, https://doi.org/10.3390/ toxins4111024 